\title{
Behavioral and electroencephalographic analysis of seizures induced by intra- hippocampal injection of granulitoxin, a neurotoxic peptide from the sea anemone Bunodosoma granulifera
}

A.N.C. Santana ${ }^{1}$ E.M. Trindade-Filho', R.B. Cunha ${ }^{3}$, M.V. Sousa ${ }^{3}$, E.A. Cavalheiro ${ }^{2}$ and K.M. Carvalho ${ }^{1}$

\author{
${ }^{1}$ Laboratório de Neurofarmacologia, Departamento de Ciências Fisiológicas, \\ Universidade Estadual do Ceará, Fortaleza, CE, Brasil \\ ${ }^{2}$ Laboratório de Neurologia Experimental, Departamento de Neurologia e \\ Neurocirurgia, Universidade Federal de São Paulo, São Paulo, SP, Brasil \\ ${ }^{3}$ Centro Brasileiro de Serviços e Pesquisas em Proteínas, Departamento de Biologia \\ Celular, Universidade de Brasília, Brasília, DF, Brasil
}

\section{Correspondence \\ K.M. Carvalho \\ Laboratório de Neurofarmacologia \\ Departamento de Ciências \\ Fisiológicas, CCS, UEC \\ Rua Paranjana, 1700 \\ 60740-000 Fortaleza, CE \\ Brasil \\ Fax: +55-85-287-7171 \\ E-mail: carvalhokris@ hotmail.com}

Presented at the XV Annual Meeting of the Federação de Sociedades de Biologia Experimental, Caxambu, MG, Brazil, August 23-26, 2000

Research supported by CNPq, FINEP, FUNCAP, CAPES and FAPESP.

Received April 12, 2000 Accepted March 15, 2001

\section{Abstract}

In this study, the behavioral and electroencephalographic (EEG) analysis of seizures induced by the intrahippocampal injection in rats of granulitoxin, a neurotoxic peptide from the sea anemone Bunodosoma granulifera, was determined. The first alterations occurred during microinjection of granulitoxin $(8 \mu \mathrm{g})$ into the dorsal hippocampus and consisted of seizure activity that began in the hippocampus and spread rapidly to the occipital cortex. This activity lasted 20-30 s, and during this period the rats presented immobility. During the first 40-50 min after its administration, three to four other similar short EEG seizure periods occurred and the rats presented the following behavioral alterations: akinesia, facial automatisms, head tremor, salivation, rearing, jumping, barrel-rolling, wet dog shakes and forelimb clonic movements. Within 40-50 min, the status epilepticus was established and lasted 8-12 h. These results are similar to those observed in the acute phase of the pilocarpine model of temporal lobe epilepsy and suggest that granulitoxin may be a useful tool not only to study the sodium channels, but also to develop a new experimental model of status epilepticus.

Three decades ago, pharmacologists and chemists were beginning to research new marine products $(1,2)$. Pharmacological tests on these new toxins began with studies on the central nervous system and ionic channels, with later studies at the level of the heart, bowel and vascular permeability. Some of these new substances have been used as scientific tools to understand some aspects
Key words

- Bunodosoma granulifera

- Granulitoxin

- Sea anemones

- Toxic peptides

- Seizure

- Electroencephalographic assay of cellular biochemistry, including the ionic channels, and others have been used as pharmaceutical products (3).

The sea anemones occupy a prominent position in this branch of research. These animals possess specialized structures, the tentacles, that contain a wide variety of toxins which are used in the capture of prey, as well as for defense against predators. Among 
these toxins, the peptides that act by binding to the ionic channels, especially to the voltage-gated sodium channels, are the substances most extensively studied and characterized (4). They act similarly to $\alpha$-scorpion toxins, inhibiting the inactivating phase of sodium currents during depolarization and stabilizing sodium channels in the open state without affecting the activation process (5). The sea anemone peptides have been classified into four classes according to their structural characteristics (4): a) type 1 class, comprising long polypeptides isolated from the genera Anthopleura and Anemonia, members of the family Actiniidae; b) type 2 class, comprising long polypeptides isolated from the genera Radianthys and Stichodactyla, members of the family Stichodactylidae; c) type 3 class, comprising long polypeptides isolated from the genus Calliactis, and d) type 4 class, comprising short polypeptides isolated from the genus Parasicyonis.

These toxic sea anemone peptides may act predominantly as cardiac stimulants or as neurotoxins according to the degree of affinity with the isoforms of cardiac or neuronal sodium channels $(4,6)$. The cardiac stimulant type 1 peptides, such as anthopleurin-A, anthopleurin-B and anemone toxin (ATX-II), have been well studied and their possible useful applications as therapeutic agents with a combination of positive inotropic and antiarrhythmic activities in human heart diseases have been suggested $(4,7)$. The pharmacological effects of some anemone peptides on the nervous system have also been studied, such as the effect of a central stimulant substance isolated from the sea anemone Stoichactis kenti on mouse brain monoamines (8), the potent excitatory effect of anthopleurin-B on frog spinal cord (9), the possible application of ShI as an insecticide based on its negligible mammalian neurotoxicity as compared to its potent neurotoxicity in crustacea $(4,10)$, the ATXII-induced increase in persistent sodium current and its effects on the firing properties of rat neocortical pyramidal neurones (11), and the synaptosomal glutamate release induced by fraction $\mathrm{Bc} 2$ from the sea anemone Bunodosoma caissarum venom (12).

However, still with respect to the pharmacological effects on the central nervous system, no electroencephalographic (EEG) studies have been conducted thus far using sea anemone peptides. In the present study, the behavioral and EEG analysis of seizures produced by granulitoxin (GRX), a new neurotoxic peptide of class type 1 recently isolated from the sea anemone $B$. granulifera (13), was determined.

GRX from the sea anemone $B$. granulifera was purified as previously described (13). The animals used were male Wistar rats, 200-250 g in weight, housed individually under environmentally controlled conditions (a 12-h light/dark cycle with lights on at 6:00 am, $22-24^{\circ} \mathrm{C}, 45-55 \%$ humidity) with free access to food and water. The rats were anesthetized with $3 \mathrm{ml} / \mathrm{kg}$ of a Nembutalchloral hydrate mixture $(1 \mathrm{~g}$ Nembutal, $4 \mathrm{~g}$ chloral hydrate dissolved in $100 \mathrm{ml}$ saline) and placed in a stereotaxic frame (David Kopf Instruments, Tujunga, CA, USA). A unilateral guide cannula (21 gauge stainless steel) was then chronically implanted into the dorsal hippocampus (CA1-CA3 areas) with the following coordinates: AP $-3.3, \mathrm{~L}$ $+2.5, \mathrm{~V}-3.5$ (14) using a rapid-setting methyl methacrylate cement (Orto-Class, Clássico São Paulo, São Paulo, SP, Brazil), that fixed the cannulae to the skull by means of stainless steel anchor screws. The stainless steel stylets terminating $0.2 \mathrm{~mm}$ beyond the tip of the guide cannula kept them open prior to microinjection. After surgery, each animal was housed individually and allowed to recover for a period of 4-5 days. The microinjections were performed with an injection cannula (27 gauge) connected to a $1-\mu 1$ Hamilton syringe by a polyethylene tube. GRX was dissolved in a volume of $1 \mu 1$ and microinjected at the rate of $0.25 \mu \mathrm{l} / \mathrm{ml}$. The injection cannula was kept in the guide can- 
nula for an additional $1 \mathrm{~min}$ to allow adequate absorption by the surrounding tissue. For depth EEG recordings, bipolar twisted electrodes were stereotaxically positioned in the dorsal hippocampus and anchored to the skull with dental acrylate. The stereotaxic coordinates were as follows: AP $-4.3, \mathrm{~L}+2.5$, V -3.5 (14). Surface recordings were obtained from jeweller screws positioned bilaterally over the occipital cortex. Another screw placed in the frontal sinus served as reference electrode. The signals under investigation were amplified using a Berger electroencephalograph (time constant $0.03 \mathrm{~s}$ and high cutoff filter $15 \mathrm{~Hz}$ ). The rats were assigned at random to the experimental and control groups $(\mathrm{N}=4-6)$ and to the subsequent times of behavioral and EEG testing. The EEG recordings and behavioral observations were carried out in a Plexiglas compartment $(30 \times 30 \times 45 \mathrm{~cm})$ between 8:00 am and 6:00 pm. Before EEG monitoring, each animal was individually placed in the recording compartment and allowed $15 \mathrm{~min}$ for habituation to the recording set-up. The baseline EEG recordings were obtained for $15 \mathrm{~min}$ and then the animal was injected into the hippocampus with GRX. Subsequently, EEG recordings were obtained continuously and behavior was noted for periods ranging from 2 to $3 \mathrm{~h}$ following the intracerebral microinjections. Additional recordings were obtained between 5-6, 8-9, 11-12, 24-28, 48-52 and 72-76 h. The correct placement of the implanted electrodes and guide cannulae was checked histologically in cresyl violet-stained serial sections as previously described (15).

The microinjection of $4 \mu \mathrm{g}$ GRX into the dorsal hippocampus did not produce significant EEG or behavioral changes. However, the first alterations occurred during the microinjection of $8 \mu \mathrm{g}$ GRX and consisted of seizure activity that began in the hippocampus and spread rapidly to the occipital cortex (Figure 1B). This activity lasted up to 20-30 $\mathrm{s}$, and during this period the rats presented immobility. During the first 40-50 min after its administration, three to four other similar short EEG seizure periods occurred (Figure 1C) and the rats presented the following behavioral alterations: akinesia, facial automatisms, head tremor, salivation, rearing, jumping, barrel-rolling, wet dog shakes and forelimb clonic movements. Although some of these behavioral alterations were present during the EEG seizure periods, they were also observed without EEG alterations in dorsal hippocampus and occipital cortex. However, this does not rule out the possibility of epileptogenic potentials occurring in other areas of the brain where the electrodes were not implanted.

Status epilepticus was established within 40-50 min (Figure 1D) and during this period the animals presented generalized convulsions alternating with behavioral changes similar to those that occurred during the period of $50 \mathrm{~min}$ after GRX injection. Status epilepticus lasted 8-12 $\mathrm{h}$ and was followed by a progressive normalization of the EEG and behavior that returned to the pre-GRX administration pattern within the next $24 \mathrm{~h}$.

As shown in the EEG assay, the intrahip-

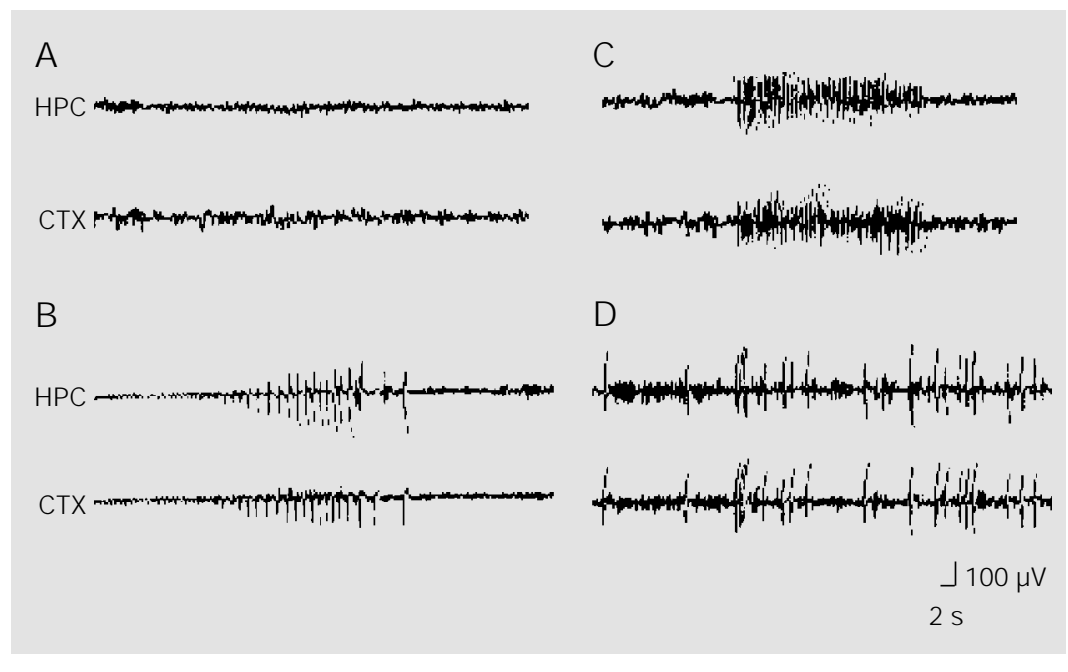

Figure 1. Electroencephalographic recordings illustrating the changes produced by intrahippocampal injection of $8 \mu \mathrm{g}$ of granulitoxin (GRX). A, Pre-toxin control recordings; B, seizure activity period observed $90 \mathrm{~s}$ before the end of GRX injection; $C$, seizure activity period observed 15 min after GRX injection, and D, status epilepticus observed 50 min after GRX injection. Records were obtained from occipital cortex (CTX) and hippocampus (HPC). 
pocampal injection of GRX $(8 \mu \mathrm{g})$ in rats produced epileptogenic activity and affected animal behavior in a significant manner. Similar results were obtained with other purified neurotoxins and venoms. Kainic acid, an algal excitotoxin, at doses less than those causing cell damage induced seizures of hippocampal origin resembling the human complex partial epilepsy arising from limbic structures (16). The total venom of the South American rattlesnake Crotalus durissus terrificus injected intrahippocampally (15) and its purified toxins, such as crotamine (17) injected intraventricularly, and convulxin (18) and gyroxin (19) injected intravenously, induced strong epileptiform effects.

Furthermore, intrahippocampal injections of GRX in rats showed important results similar to those observed during the acute period after systemic administration of pilocarpine, a potent muscarinic agonist that has been used to establish an experimental model of temporal lobe epilepsy (20). During the first 30-40 min after their administration to rats, GRX and pilocarpine produce similar behavioral signs and similar EEG changes, and after 40-50 min, both also produce simi- lar status epilepticus. These observations suggest that the seizures induced by GRX may originate, at least in part, from the same neural systems responsible for pilocarpine seizures in the acute period. In the future, it will be important to investigate if GRX, like pilocarpine, may also induce brain lesions that are responsible for the chronic period of seizures that may persist for a long time (6 months) (20).

The N-terminal amino acid sequence of GRX (AKTGILDSDGPTVAGNSLSGT) presents a partial degree of homology with those of other toxins from sea anemones such as B. caissarum, Anthopleura fuscoviridis and Anemonia sulcata (13), suggesting that this toxin may be classified as a class type 1 polypeptide that seems to act by prolonging action potentials of excitable tissues by slowing down the inactivation process of the voltage-gated sodium channel (5).

In conclusion, the results presented here suggest that GRX may be a useful tool not only to study sodium channels, but also to develop a new experimental model of status epilepticus, opening new perspectives in the field of sea anemone toxin research.

\section{References}

1. Ireland CM, Copp BR, Foster MP, McDonald LA, Radisky DC \& Swersey J C (1993). Biomedical potential of marine natural products. In: Attaway $\mathrm{DH} \&$ Zaborsky OR (Editors), Marine Biotechnology. Vol. I. Plenum Press, New York, 1-43.

2. Faulkner DJ (1996). Marine natural products. Natural Product Reports, 13: 75-125.

3. Baker JT, Borris RP, Carté B, Cragg GM, Gupta MP, Iwu MM, Madulid DR \& Tyler VE (1995). Natural product drug discovery and development: new perspectives on international collaboration. J ournal of Natural Products, 58: 1325-1357.

4. Norton RS (1991). Structure and structure-function relationships of sea anemone proteins that interact with the sodium channel. Toxicon, 29: 1051-1084.

5. Benoit E (1998). Mechanism of action of neurotoxins on the inactivation of voltage- gated sodium channels. Comptes Rendus des Séances de la Société de Biologie et de Ses Filiales, 192: 409-436.

6. Béress L \& Béress R (1975). Purification of three polypeptides with neuro- and cardiotoxic activity from the sea anemone Anemonia sulcata. Toxicon, 13: 359-367.

7. Benzinger GR, Kyle J W, Blumenthal KM \& Hanck DA (1998). A specific interaction between the cardiac sodium channel and site 3 toxin Ap-B. J ournal of Biological Chemistry, 273: 80-84.

8. Turlapaty P, Shibata S, Norton TR \& Kuchii M (1973). Effects of a central stimulant substance isolated from the sea anemone Stoichactis kenti on brain monoamines of the mouse. European J ournal of Pharmacology, 24: 359-365.

9. Kudo Y \& Shibata S (1980). The potent excitatory effect of a novel polypeptide, anthopleurin-B, isolated from a sea anem- one (Anthopleura xanthogrammica) on the frog spinal cord. J ournal of Pharmacology and Experimental Therapeutics, 214: 443448.

10. Pauron D, Barhanin J \& Lazdunski M (1985). The voltage-dependent $\mathrm{Na}^{+}$channel of insect nervous system identified by receptor sites for tetrodotoxin, and scorpion and anemone toxins. Biochemical and Biophysical Research Communications, 131: 1226-1233.

11. Mantegazza M, Franceschetti $S \&$ Avanzini G (1998). Anemone toxin (ATX II)-induced increase in persistent sodium current: effects on the firing properties of rat neocortical pyramidal neurones. J ournal of Physiology, 507: 105-116.

12. Migues PV, Leal RB, Mantovani M, Nicolau M \& Gabilan NH (1999). Synaptosomal glutamate release induced by the fraction $\mathrm{BC} 2$ from the venom of the sea anemone 
Bunodosoma caissarum. NeuroReport, 10: 67-70.

13. Santana ANC, Leite $A B$, França MSF, França L, Vale OC, Cunha RB, Ricart CAO, Sousa MV \& Carvalho KM (1998). Partial sequence and toxic effects of granulitoxin, a neurotoxic peptide from the sea anemone Bunodosoma granulifera. Brazilian J ournal of Medical and Biological Research, 31: 1335-1338.

14. Paxinos G \& Watson C (1982). The Rat Brain in Stereotaxic Coordinates. Academic Press, Sydney.
15. Mello LEAM \& Cavalheiro EA (1989). Behavioural, electroencephalography and neuropathological effects of the intrahippocampal injection of the venom of the South American rattlesnake (Crotalus durissus terrificus). Toxicon, 27: 188-199.

16. Fisher RS (1989). Animal models of the epilepsies. Brain Research Reviews, 14: 245-278.

17. Habermann E \& Cheng-Raude D (1975). Central neurotoxicity of apamin, crotamin, phospholipase A and alpha-amanitin. Toxicon, 13: 465-473.
18. Prado-FranceschiJ \& Vital Brazil O (1981). Convulxin, a new toxin from the venom of South American rattlesnake Crotalus durissus terrificus. Toxicon, 19: 875-887.

19. Seki C, Vidal J C \& Barrio A (1980). Purification of gyroxin from a South American rattlesnake (Crotalus durissus terrificus) venom. Toxicon, 18: 235-247.

20. Cavalheiro EA (1995). The pilocarpine model of epilepsy. Italian J ournal of Neurological Sciences, 16: 33-37. 